\title{
Cortical Spreading Depression Promotes Persistent Mechanical Sensitization of Intracranial Meningeal Afferents: Implications for the Intracranial Mechanosensitivity of Migraine
}

\author{
Jun Zhao, ${ }^{1,2}$ and ${ }^{-D a n}$ Levy ${ }^{1,2}$ \\ DOI:http://dx.doi.org/10.1523/ENEURO.0287-16.2016 \\ ${ }^{1}$ Department of Anesthesia, Critical Care and Pain Medicine, Beth Israel Deaconess Medical Center, Boston, 02215 \\ MA, and ${ }^{2}$ Harvard Medical School, Boston, 02115 MA
}

\begin{abstract}
Migraine is one of the most common and disabling diseases in the world. A major feature of migraine headache is its aggravation by maneuvers that momentarily increase intracranial pressure. A key hypothesis implicates mechanical sensitization of trigeminal afferents that innervate the intracranial meninges in mediating this feature of migraine. However, whether such pain-related neural response actually develops under endogenous conditions that are linked specifically to migraine remains to be established. Single-unit recordings in the trigeminal ganglion of anesthetized male rats were combined with quantitative mechanical stimulation of the cranial dura mater to determine whether cortical spreading depression (CSD), an endogenous migraine-triggering event, affects the mechanosensitivity of meningeal afferents. CSD gave rise to an almost threefold increase in the magnitude of the responses to mechanical stimuli in 17 of 23 of the afferents tested. CSD-evoked meningeal afferent mechanosensitization occurred with a delay of $23.1 \pm 2.2 \mathrm{~min}$ and lasted $64.1 \pm 6.8 \mathrm{~min}$ in recording sessions that lasted for $90 \mathrm{~min}$ and for $177.5 \pm 22.1 \mathrm{~min}$ in recording sessions that were extended for $240 \mathrm{~min}$. Some of the sensitized afferents also developed a shorter-lasting increase in their ongoing discharge rate that was not correlated with the increase in their mechanosensitivity, suggesting that CSD-evoked meningeal afferent sensitization and increase in ongoing activity are independent phenomena. These novel findings support the notion that mechanical sensitization of meningeal afferents serves as a key nociceptive process that underlies the worsening of migraine headache during conditions that momentarily increase intracranial pressure.
\end{abstract}

Key words: afferent; cranial meninges; headache; mechanosensitization; migraine; trigeminal

\section{Significance Statement}

Migraine headache is associated with symptoms suggestive of exaggerated intracranial mechanosensitivity. Enhanced mechanosensitivity of meningeal afferents could mediate this migraine feature, but whether such neural response occurs under endogenous conditions linked specifically to migraine remains a matter of speculation. Elicitation of cortical spreading depression (CSD), an endogenous migraine trigger, led to a pronounced and persistent increase in the mechanosensitivity of meningeal afferents that was not correlated with the additional shorter-lasting increases in the afferents' ongoing activity. Mechanosensitization of meningeal afferents, induced by CSD and possibly other migraine triggers, could serve as a key nociceptive process that underlies the intracranial pain of migraine headache and its worsening during conditions that momentarily increase intracranial pressure, such as rapid head movements and coughing. 


\section{Introduction}

Migraine is the third most prevalent and seventh most disabling disease in the world, affecting about $15 \%$ of the adult population worldwide (Stovner et al., 2007; Steiner et al., 2013). Although the exact biological conditions underlying migraine remain unclear, the head pain of migraine is believed to be mediated by trigeminal primary afferent neurons that innervate the cranial meninges and their related large vessels (Messlinger, 2009; Noseda and Burstein, 2013). One of the key features of migraine pain points to the presence of increased intracranial mechanosensitivity, similar to the headaches that accompany certain intracranial pathologies, in particular aggravation of the pain by maneuvers that momentarily increase intracranial pressure such as coughing, straining, bending over, or rapid head movement (Blau and Dexter, 1981). One mechanism that was proposed to play an important role in mediating this key feature of the migrainous headache is enhanced mechanosensitivity (i.e., mechanical sensitization) of intracranial trigeminal meningeal afferents (Strassman et al., 1996; Strassman and Levy, 2006; Olesen et al., 2009). Previous studies documented the development of mechanical sensitization in meningeal afferents in response to direct stimulation of their receptive fields (RFs) using exogenous application of painproducing inflammatory agents that are not specific to migraine (Strassman et al., 1996; Levy and Strassman, 2002, 2004). Thus, it remains unknown whether such meningeal afferent sensitization can also develop under endogenous conditions that are linked specifically to migraine.

Cortical spreading depression (CSD), an abnormal selfpropagating slow wave of neuronal and glial depolarizations, has been proposed as the neural substrate of the abnormal visual symptoms (i.e., visual aura) that often precede the headache of migraine (Hadjikhani et al., 2001; Cao et al., 2002; Charles and Baca, 2013). CSD has been hypothesized to promote the activation of the meningeal sensory pathway and the ensuing headache of migraine (Moskowitz, 1984). The notion that CSD in rodents can provide an experimental platform to investigate neural mechanisms underlying migraine headache (Moskowitz et al., 1993) has led to important findings that implicate CSD as a trigger of meningeal afferent-evoked meningeal

Received September 20, 2016; accepted November 14, 2016; First published December 05, 2016.

Authors report no conflict of interest.

Author contributions: JZ designed research, performed research, analyzed data. $\mathrm{DL}$ designed research, analyzed data, wrote the paper.

The study was supported by grants from the NIH/NINDS (NS086830, NS078263 to DL).

Acknowledgments: The authors thank Dr. Andrew Strassman for valuable comments on the manuscript.

Correspondence should be addressed to Dan Levy, PhD, Department of Anesthesia, 330 Brookline Ave., DA717, Boston MA 02215. E-mail: dlevy1@bidmc.harvard.edu.

DOI:http://dx.doi.org/10.1523/ENEURO.0287-16.2016

Copyright (C) 2016 Zhao and Levy

This is an open-access article distributed under the terms of the Creative Commons Attribution 4.0 International, which permits unrestricted use, distribution and reproduction in any medium provided that the original work is properly attributed. vasodilation and activation of the central headache pain pathway (Bolay et al., 2002; Zhang et al., 2010, 2011; Karatas et al., 2013; Zhao and Levy, 2015) and as such, a potential target for migraine pain treatment (Ayata et al., 2006).

Here, in vivo extracellular single unit recording of mechanosensitive meningeal afferents was combined with quantitative mechanical stimulation of the cranial dura mater to test for the first time the hypothesis that CSD is an important endogenous cortical process that can lead to the development of mechanical sensitization of trigeminal afferents that innervate the intracranial meninges. The results suggest that CSD can promote a pronounced and persistent increase in the mechanosensitivity of meningeal afferents. The data further suggest that the mechanisms underlying the development and maintenance of meningeal afferent mechanical sensitization and those responsible for the increase in the afferents' ongoing activity after CSD are distinct. The development of mechanical sensitization of meningeal afferents after CSD further substantiates the role of these trigeminal sensory neurons in mediating migraine headache. Mechanical sensitization of meningeal afferents could serve as a key neural process that underlies the worsening of the headache during conditions that momentarily increase intracranial pressure, such as rapid head movements and coughing.

\section{Materials and Methods}

\section{Animals}

Male Sprague-Dawley rats (250-350 g) were used throughout the study. All animal experiments were conducted in accordance with the experimental protocol approved by the institutional Animal Care and Use Committee.

\section{Surgery and electrophysiological recordings}

Animals were deeply anesthetized with urethane (1.2$1.5 \mathrm{~g} / \mathrm{kg}$, i.p.). Core temperature was kept at $37-38^{\circ} \mathrm{C}$ using a homoeothermic control system. Animals breathed spontaneously room air enriched with $\mathrm{O}_{2}$. Physiological parameters were collected throughout the experiments, and data were collected only from animals exhibiting physiological levels of oxygen saturation (>95\%), heart rate (350-450 bpm), and end-tidal $\mathrm{CO}_{2}$ (3.5-4.5\%). With a saline-cooled dental drill, one craniotomy was made to expose the left transverse sinus as well as the adjacent cranial dura extending $\sim 2 \mathrm{~mm}$ rostral to the sinus. Another small burr hole $(0.5-\mathrm{mm}$ diameter) was made to expose a small area of dura above the frontal cortex to allow the induction of CSD. The exposed dura was bathed with a modified synthetic interstitial fluid containing 135 $\mathrm{mm} \mathrm{NaCl}, 5 \mathrm{~mm} \mathrm{KCl}, 1 \mathrm{~mm} \mathrm{MgCl}_{2}, 5 \mathrm{~mm} \mathrm{CaCl}_{2}, 10 \mathrm{~mm}$ glucose, and $10 \mathrm{~mm}$ HEPES, pH 7.2. Single-unit activity of meningeal afferents (1 unit/rat) was recorded in the ipsilateral (left) trigeminal ganglion using a $50-$ to $100-\mathrm{k} \Omega$ platinum-coated tungsten microelectrode (FHC, Bowdoin, ME). To avoid the induction of uncontrolled CSDs in the ipsilateral cortex, the recording electrode was advanced into the left ganglion through a contralateral an- 
gled approach, which spares the ipsilateral cortex. Meningeal afferent neurons were identified by their constant latency response to single shock stimulation applied to the dura above the ipsilateral transverse sinus $(0.5-\mathrm{ms}$ pulse, $5 \mathrm{~mA}, 0.5 \mathrm{~Hz}$ ). The response latency was used to calculate conduction velocity (CV), based on a conduction distance to the trigeminal ganglion of $12.5 \mathrm{~mm}$ (Strassman et al., 1996). Neurons were classified as either C units $(\mathrm{CV} \leq 1.5 \mathrm{~m} / \mathrm{sec})$ or $A \delta$ units $(1.5<\mathrm{CV} \leq 5 \mathrm{~m} / \mathrm{s})$. All meningeal afferents tested were mechanosensitive when probed with von Frey filaments $(0.03-6.9 \mathrm{~g}$, Stoelting Co., Chicago, IL), and had at least 1 RF located on the left transverse sinus or its vicinity $(<1 \mathrm{~mm})$. Neural activity was digitized, and a real-time waveform discriminator (Spike 2 software, CED, Cambridge, UK) was used to create and store a template for the action potential evoked by electrical stimulation, which was used later to acquire and analyze the ongoing activity of the neurons and the activity evoked by mechanical stimulation and CSD.

\section{Detection of mechanical sensitization}

Mechanical responsiveness was quantitatively determined in each afferent by recording the responses to mechanical stimuli (100-ms rise time, 2-s width, 120-s interstimulus interval) delivered using a feedbackcontrolled mechanical stimulator (Series 300B, Aurora Scientific, Aurora, ON, Canada) and a custom-written script for Spike 2. Stimulus trials for testing changes in mechanosensitivity included one threshold stimulus $(\mathrm{TH}$, which normally evoked a $1-$ to $3-\mathrm{Hz}$ response) followed by a suprathreshold stimulus (STH, usually $\times 2$ of the threshold; 8- to $10-\mathrm{Hz}$ responses) and were delivered every 15 min throughout the experiment. These parameters were used to avoid potential desensitization to the mechanical stimuli. Ongoing afferent discharge rate was recorded continuously between the stimulation trials. Baseline ongoing activity and responses to mechanical stimulation were determined during at least four consecutive trials before the elicitation of CSD. Only units that exhibited consistent responses (variation of $<0.5 \mathrm{~Hz}$ for $\mathrm{TH}$ responses and $<1.5 \mathrm{~Hz}$ for STH responses) during baseline recordings were tested further.

\section{Induction and monitoring of CSD}

In each experiment, a single CSD episode was induced in the frontal cortex by pinpricking the cortex with a fine glass micropipette (diameter $10 \mu \mathrm{m}$ ) at $\sim 2 \mathrm{~mm}$ depth for $2 \mathrm{~s}$. CSD was induced in the frontal cortex to avoid potential damage to the meningeal tissue near the RF of the studied afferents, which could have led to their sensitization. The occurrence of a CSD episode was determined noninvasively by recording simultaneously changes in cerebral blood flow (CBF) using laser Doppler flowmetry, with the probe positioned within the craniotomy, just above $(1 \mathrm{~mm})$ the exposed dura, near $(\sim 1 \mathrm{~mm})$ the RF of the recorded unit. Induction of CSD was considered successful when the typical hemodynamic signature characterized by a large transient $(\sim 1-$ to 2 -min) cortical cerebral hyperemia, followed by persistent $(>1-h)$
post-CSD oligemia (Fordsmann et al., 2013), was observed.

\section{Data analyses}

Offline analyses for afferent responses were conducted using template matching in Spike 2. Average data are presented as the mean \pm SEM. Average data in figures is presented as the mean $\pm 95 \%$ confidence interval $(\mathrm{Cl})$. A neuron was deemed sensitized only if the following criteria were fulfilled: $\mathrm{TH}$ and/or STH responses increased to a level greater than the upper endpoint of the $95 \% \mathrm{Cl}$ calculated for the baseline mean; sensitization began during the first 60 min post-CSD; and sensitization lasted for at least $30 \mathrm{~min}$ (i.e., two consecutive trials). CSD-evoked increases in afferents' ongoing activity were considered if the firing rate increased above the upper end point of the $95 \% \mathrm{Cl}$ calculated for the baseline mean for $>10 \mathrm{~min}$. Group differences were analyzed using two-tailed, Fisher's exact test. Statistical differences were analyzed using two-tailed unpaired $t$-test or Mann for normally distributed data and with the Mann-Whitney rank sum test when data failed the normality test (Kolmogorov-Smirnov test) or equal variance test. To examine correlations between neural activation and sensitization parameters, either Pearson or Spearman correlation coefficient tests were used based on data normality. Results were considered to be significant at $p<0.05$. Superscript letters listed with $p$-values correspond to the statistical tests shown in Table 1.

\section{Results}

\section{CSD evokes a pronounced and persistent mechanical sensitization of meningeal afferents}

The development of changes in mechanosensitivity of meningeal afferents in relation to the onset of CSD was studied by recording simultaneously the CSD-evoked CBF changes and single-unit activity in response to quantitative mechanical stimuli of the afferents' meningeal RF (Fig. 1). The effect of CSD on the afferents' responsiveness was investigated in 23 afferents $(9 \mathrm{~A} \delta$ and 14 C-units). In control experiments, in which no CSD was induced, time-related changes in mechanosensitivity were examined in 12 meningeal afferents $(5 \mathrm{~A} \delta$ and 7 C-units).

Single CSD events were successfully evoked in all cases where the frontal cortex was stimulated and were associated with a typical hemodynamic signature characterized by a brief $(\sim 1-\mathrm{min})$ cortical cerebral hyperemia followed by a persistent $(>1-h)$ post-CSD oligemia (Fordsmann et al., 2013; Gariepy et al., 2016; see also Fig. 2). After CSD, persistent mechanical sensitization, longer than 30 min of either TH and/or STH increased firing, was noted in 17 of $23(\sim 74 \%)$ of the neurons (see an example in Fig. 2). We could not identify any significant differences between the response properties of afferents that became sensitized after CSD and of those that did not, including in baseline mechanosensitivity, number of distinct RFs, or baseline ongoing activity before the induction of CSD (Table 2, $p>0.05^{\mathrm{a}-\mathrm{c}}$ for all). 


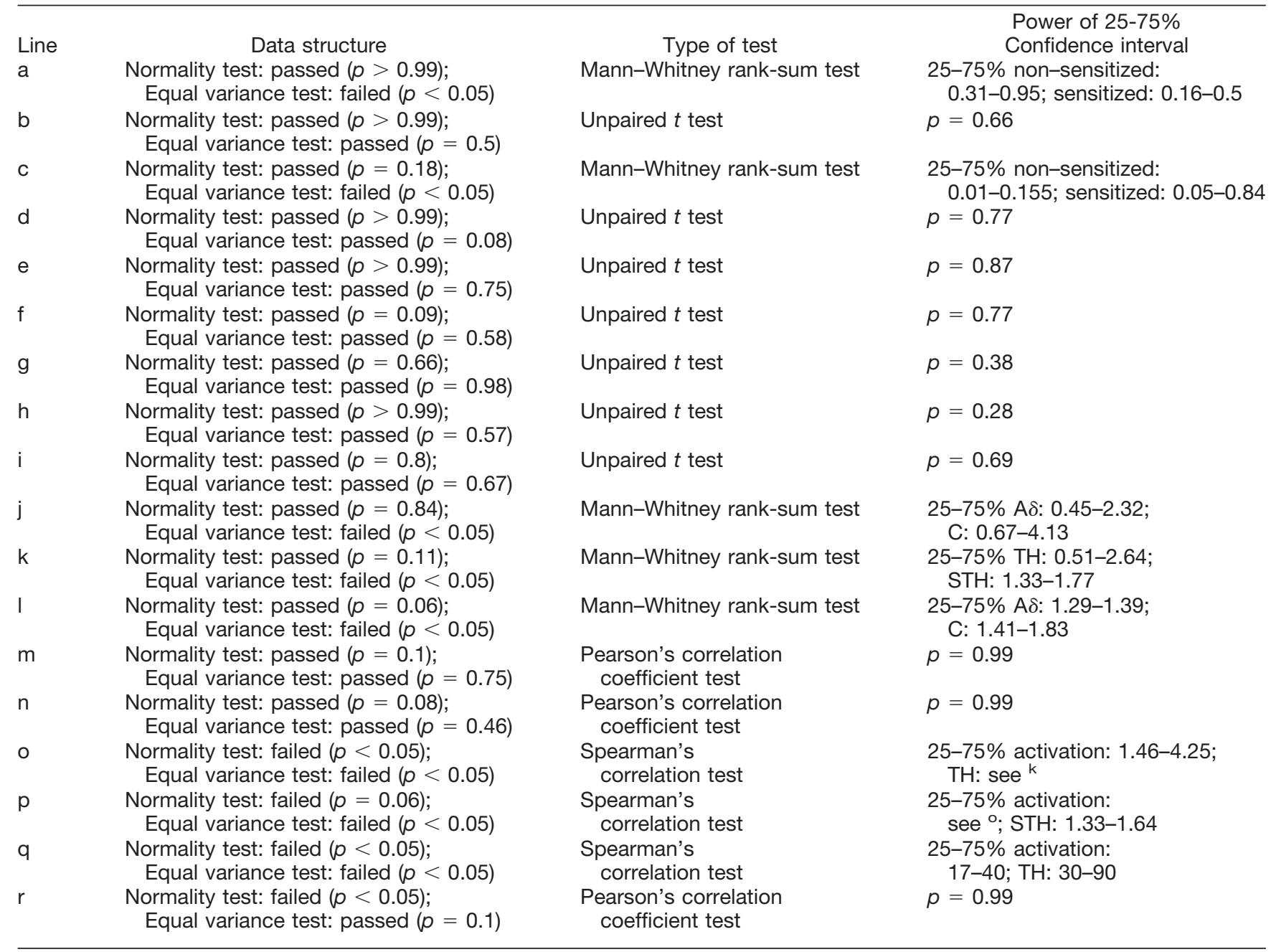

In time control experiments, in which responses to mechanical stimuli were tested for at least $180 \mathrm{~min}, 5$ of 12 (3 C-units, 2 A $\delta$ ) displayed a slight decline in mechanical responsiveness over time. In 6 of 12 units $(3 \mathrm{~A} \delta, 3 \mathrm{C}$ units), mechanical responsiveness remained stable over time, and in 1 of 12 units (C-unit) there was an increase in mechanical responsiveness (only at the $\mathrm{TH}$ level and for only $30 \mathrm{~min}$ ). This frequency of sensitization in the control experiments was significantly lower than that observed after the induction of CSD ( $p<0.001$, Fisher's exact test). Among the afferent population that developed mechanical sensitization response following CSD, there was no difference in the propensity to become sensitized between the $A \delta(7 / 9)$ and the $C$ units (10/14). These two neuronal populations also did not differ significantly with regard to the CSD sensitization rates at the TH or STH levels (Table 3), with most of the sensitized afferents (10/17) showing simultaneous sensitization at both the $\mathrm{TH}$ and STH levels.

The onset latency of the CSD-induced mechanical sensitization ranged between 15 and 45 min, with most units (13/17) showing sensitization already at the first trial after CSD (i.e., at $15 \mathrm{~min}$ ). As Fig. $3 \mathrm{C}$ depicts, the average onset latency of the $\mathrm{TH}$ sensitization response was $18.7 \pm 1.9$ min, and there was no significant difference between the sensitization latency of the $A \delta$ units $(18.7 \pm 3.7 \mathrm{~min})$ and the C-units $\left(23.3 \pm 5.1 \mathrm{~min}, p<0.05^{\mathrm{d}}\right)$. The average latency of the STH sensitization response was $27.5 \pm 3.6$ min, which was not statistically different than that of the $\mathrm{TH}$ response $\left(p>0.05^{\mathrm{e}}\right)$. The STH sensitization onset latencies observed for the $A \delta$ and $C$ units were not statistically different $(33.7 \pm 3.8$ vs. $22.5 \pm 4.0 \mathrm{~min}, p>$ $0.05^{f}$.

In most afferent neurons, where the sensitizing effect of CSD was recorded for up to $90 \mathrm{~min}$ after the CSD, the overall duration of the $\mathrm{TH}$ sensitization responses ranged between 30 and $90 \mathrm{~min}$ and averaged $63.7 \pm 7.6 \mathrm{~min}$ (Fig. $3 D$ ). There was no difference between the duration of the sensitization observed for the $A \delta(72.0 \pm 12.0 \mathrm{~min})$ and C-unit $(54.4 \pm 9.4 \mathrm{~min})$ populations $\left(p>0.05^{\mathrm{g}}\right)$. During the 90 -min recording time period, the overall duration of the CSD-related sensitization at the STH level also ranged between 30 and $90 \mathrm{~min}$ and averaged 64.6 $\pm 6.4 \mathrm{~min}(p>$ 0.05 vs $\mathrm{TH}^{\mathrm{h}}$ ) with no significant difference between the $A \delta$ $(57.0 \pm 8.7 \mathrm{~min})$ and $\mathrm{C}$-unit $(70.0 \pm 7.9 \mathrm{~min})$ populations ( $\left.p>0.05^{i}\right)$. In four sensitized units, in which the post-CSD 


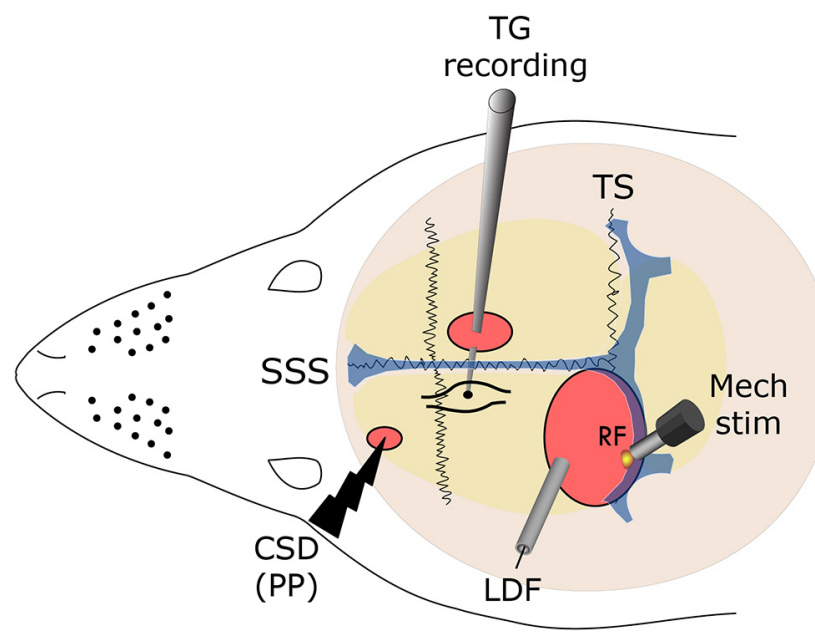

Figure 1. Experimental setup. Three skull openings (red ovals) were made. A small burr hole was made over the left frontal cortex to elicit CSD events using a pinprick (PP). Meningeal afferent activity was recorded in the left trigeminal ganglion (TG) using a tungsten microelectrode inserted through a craniotomy made over the contralateral hemisphere. An ipsilateral craniotomy was made to expose a part of the left transverse sinus (TS) and its vicinity to search for meningeal afferents with mechanical RF. Quantitative mechanical stimuli were delivered to the afferents' RF using a feedback-controlled mechanical stimulator. Laser Doppler flowmetry (LDF) probe was placed over the cortex near the stimulated afferent's RF to validate the induction of the CSD by testing related changes in cerebral blood flow. SSS, superior sagittal sinus.

recording sessions were extended to 240 min (see an example in Fig. 2), mechanically evoked responses remained elevated for 105-240 min after CSD, with an average duration of $157.5 \pm 33.3 \mathrm{~min}$ for the $\mathrm{TH}$ response and $202.5 \pm 37.5 \mathrm{~min}$ for the STH response (see also Fig. $3 D$ ). In these units, the increased responsiveness was also observed during a time when the prolonged cerebral oligemia resolved and CBF returned to baseline levels.

As Fig. $3 E$ depicts, during the sensitization state, the average increase in the $\mathrm{TH}$ response magnitude was 1.6 \pm 0.4 -fold (average peak magnitude $2.8 \pm 0.9$-fold). There was no significant difference $\left(p>0.05^{j}\right)$ between the response magnitude of the $A \delta$ units (average increase 1.5 \pm 0.5 -fold, peak increase $2.8 \pm 1.2$-fold) compared to the C-units (average increase $1.8 \pm-0.6$-fold, peak increase $2.9 \pm 1.3$-fold). The average increase in the magnitude of the STH responses was $1.5 \pm 0.1$-fold (peak increase 1.8 \pm 0.1 ), which was not significantly different from that of the $\mathrm{TH}$ response $\left(p>0.05^{\mathrm{k}}\right)$. There was no difference between the average increase in mechanosensitivity noted for the $\mathrm{A} \delta$ and that noted for the C-units $(1.3 \pm$ 0.05 -fold; peak response $1.5 \pm 0.1$-fold vs. $1.6 \pm 0.1$-fold; peak $2.0 \pm 0.1$-fold, $p>0.05^{\prime}$ ).

\section{Mechanical sensitization of meningeal afferents after CSD is not related to the development of increased ongoing activity}

To examine the possibility that the increase in ongoing activity and mechanical sensitization that develop following CSD are two unrelated processes, regression analy- ses were conducted to determine the correlation coefficients between the different parameters of the CSDevoked activation and sensitization responses (Fig. 4A-F). Among the units that displayed both activation and sensitization, there was no correlation between the neural activation onset latency and the latencies for sensitization at either the TH level (regression coefficient $R^{2}=0.06, p$ $\left.>0.05^{\mathrm{m}}\right)$ or STH level $\left(R^{2}=0.09, p>0.05^{\mathrm{n}}\right)$. No correlation was found between the average magnitude of the activation response and that of the sensitization responses, at either the TH level (correlation coefficient $R^{2}$ $\left.=0.23, p>0.05^{\circ}\right)$ or STH level $\left(R^{2}=0.11, p>0.05^{\mathrm{p}}\right)$. Finally, no correlations were found between the durations of the CSD-evoked neural activation and that of the sensitization responses at either the $\mathrm{TH}$ (regression coefficient, $\left.R^{2}=0.08, p>0.05^{9}\right)$ or STH $\left(R^{2}=0.01, p>0.05^{\eta}\right)$ level. Further analyses of the sensitization and activation response durations revealed a longer duration for the mechanical sensitization response in comparison to the duration of the increase in ongoing activity; among all the units that exhibited an increase in ongoing activity, the duration of only 3 of 15 activated units exceeded 45 min. This relative rate was significantly lower than the rate observed for units that displayed a heightened mechanosensitivity at this time point, at the TH level (10/13; $p<$ 0.01 by Fisher's exact test) as well as at the STH level (10/14 units, $p<0.001$ by Fisher's exact test).

\section{Discussion}

Mechanical sensitization of meningeal afferents has been hypothesized as a key nociceptive process that underlies the exacerbation of migraine headache during conditions that momentarily increase intracranial pressure, such as rapid head movements and coughing (Strassman et al., 1996; Strassman and Levy, 2006). The current data provide critical experimental evidence that supports this hypothesis by showing for the first time that CSD, a putative endogenous trigger of the migraine aura, is an important endogenous factor that can lead to the development of a persistent and pronounced increase in the mechanosensitivity of trigeminal afferents that innervate the cranial meninges.

Because migraine pain develops either during the aura phase or with a slight delay of $\sim 15 \min$ (Hansen et al., 2012), the finding that mechanical sensitization could be observed in many meningeal afferents already at 15 min after CSD further supports the role of CSD as an important endogenous process that participates in the genesis of migraine headache. The finding that, after CSD, the sensitization of meningeal afferents could last for hours further substantiates the role of mechanosensitive meningeal afferents in mediating the onset of migraine headache as well as contributing to its persistence during the first hours of the attack.

The current data suggest that CSD promotes increased mechanosensitivity of meningeal afferents at the $\mathrm{TH}$ and STH levels. Increased mechanosensitivity around the afferents' TH levels, which often also includes a reduction in their mechanical activation threshold (Levy and Strassman, 2002), may contribute to headache of migraine by 
A

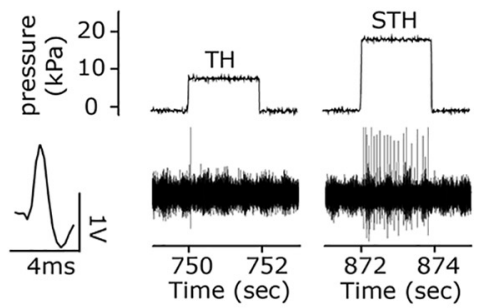

(0.5)

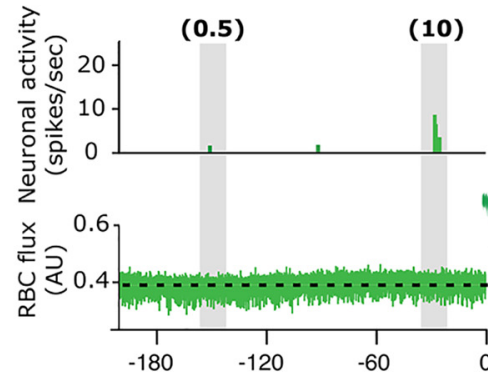

15 min post CSD

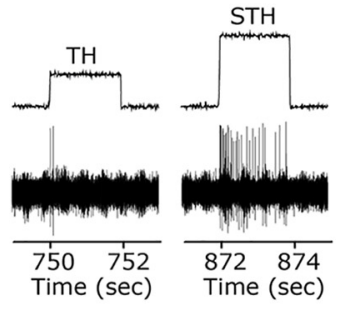

(1)

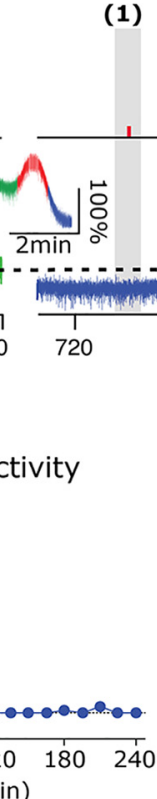

Ongoing activity

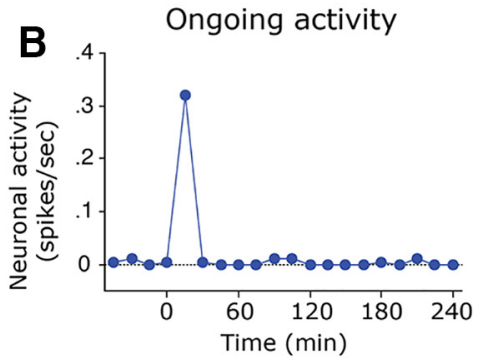

90 min post CSD

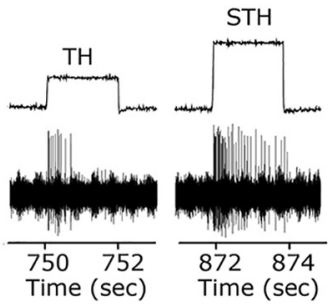

(5.5)

(14)

\section{0 min post CSD}

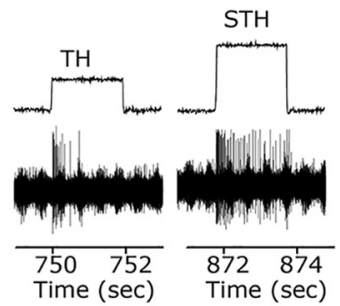

(8)
(19)

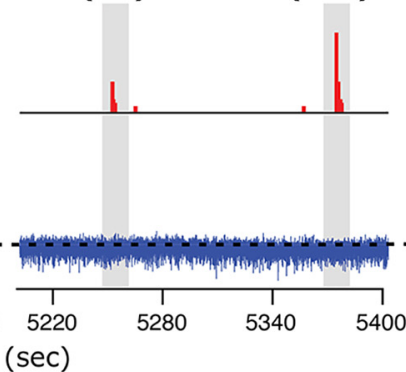

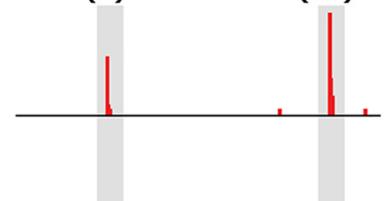

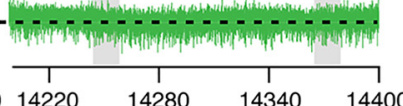

Time (sec)
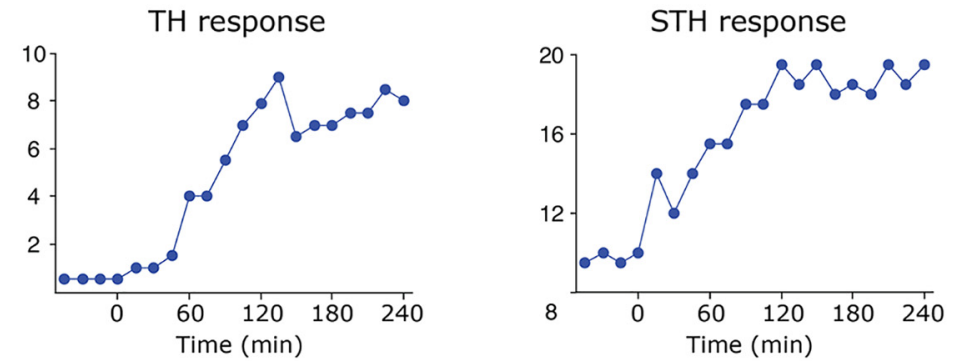

Figure 2. An example showing the development of mechanical sensitization after CSD in one C-unit meningeal afferent unit. $\boldsymbol{A}$, Top, trace examples of mechanically evoked afferent discharge to TH and STH stimuli during the last baseline stimuli trial, before the induction of CSD, and during the trials conducted at 15, 90, and 240 min after the induction of CSD. Below are matching peristimulus time histograms (PSTH, bean size $0.5 \mathrm{~s}$ ) with mechanically evoked responses (spikes/s) in parentheses. The bottom trace illustrates the CBF at baseline and during the post-CSD mechanical stimulation trials. The insert denotes the acute changes in CBF during the arrival of the CSD near the RF of the recorded afferent. Note the CSD-evoked increase (red) and decrease (blue) in CBF. Also note the reduced CBF (blue traces) present at 15 and 90 min after the onset of CSD. $\boldsymbol{B}$, Time course data depicting the level of ongoing activity, TH and STH responses of the same unit during baseline sampling and every 15 min after the induction of CSD.

allowing the afferents, in particular those that terminate on or very near meningeal blood vessels, to become activated in response to the small increase in the diameter of meningeal blood vessels seen during the attack (Amin et al., 2012, 2014) or the related stretching of the meninges. The development of meningeal vasodilatation during the headache stage may be due to an ongoing activation of meningeal afferents and the consequent release of vasodilating sensory neuropeptides, such as calcitonin

Table 2. Response properties of meningeal afferents that developed and did not develop mechanical sensitization following CSD

\begin{tabular}{lllll}
\hline Sensitization & $n$ & $\begin{array}{c}\text { Baseline } \\
\text { threshold }(\mathrm{g})\end{array}$ & $\begin{array}{c}\text { Identified } \\
\text { RFs }\end{array}$ & $\begin{array}{c}\text { Baseline ongoing } \\
\text { activity }(\mathrm{Hz})\end{array}$ \\
Sensitized & 17 & $0.5 \pm 0.2^{\mathrm{a}}$ & $2.1 \pm 0.3^{\mathrm{b}}$ & $0.4 \pm 0.1^{\mathrm{C}}$ \\
Nonsensitized & 6 & $0.5 \pm 0.2$ & $2.0 \pm 0.3$ & $0.6 \pm 0.3$
\end{tabular}

Data show the mean \pm SEM. $(a-c)$ Two-tailed unpaired $t$-test revealed no significance differences between the groups. gene-related peptide, through the process of neurogenic inflammation (Pietrobon and Moskowitz, 2012; Russo, 2015). The development of mechanical sensitization and the ensuing increased responsiveness to meningeal vessel dilatation and meningeal stretching may serve as a feed-forward mechanism that sustains the activity of the afferents and hence the headache. CSD-related sensitization of meningeal afferents at the STH level may partic-

Table 3. Rate of different types of mechanical sensitization responses in $A \delta$ and $C$ meningeal afferents following CSD

\begin{tabular}{lllllll}
\hline & \multicolumn{2}{c}{ TH only } & \multicolumn{2}{c}{ STH only } & \multicolumn{2}{c}{ TH + STH } \\
Group & $\mathrm{A} \delta$ & $\mathrm{C}$ & $\mathrm{A} \delta$ & $\mathrm{C}$ & \multicolumn{1}{c}{$\mathrm{A} \delta$} & $\mathrm{C}$ \\
CSD & $2 / 9(11)$ & $1 / 14(7)$ & $2 / 9(22)$ & $2 / 14(14)$ & $3 / 9(30)$ & $7 / 14(50)$ \\
Control & $0 / 5(0)$ & $1 / 7(8)$ & $0 / 5(0)$ & $0 / 7(0)$ & $0 / 5(0)$ & $0 / 7(0)$ \\
\hline
\end{tabular}

Data show rate (\% of responses). Sensitization at the TH and STH levels were determined according to the calculation described in the Methods. Two-tailed $\chi^{2}$ tests revealed no significant differences in the rate of the sensitization responses exhibited by the $\mathrm{A} \delta$ and $\mathrm{C}$-unit populations. 
A

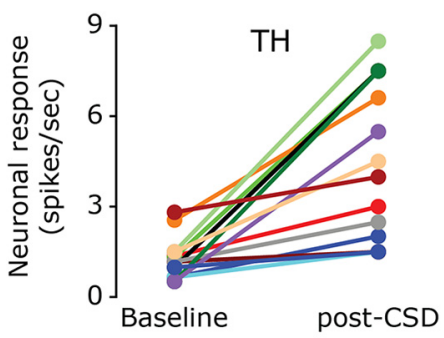

B

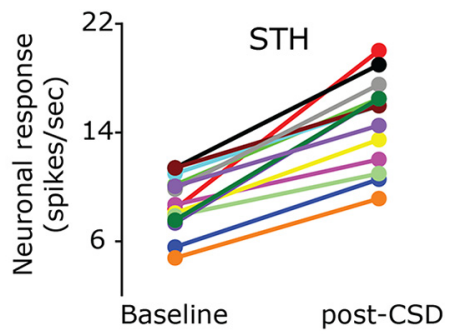

$\mathbf{E}$
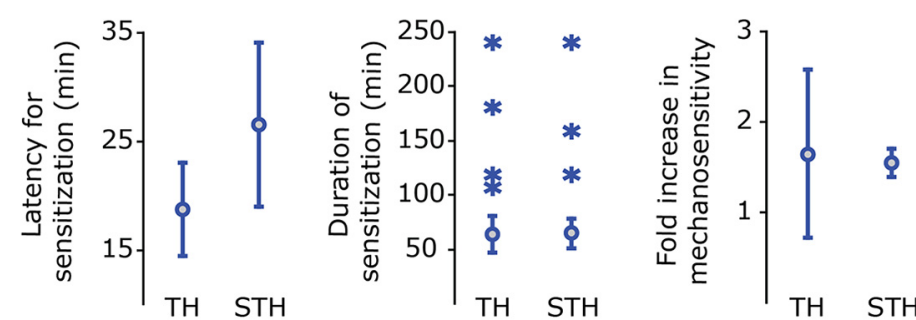

Figure 3. Summary of characteristics of the mechanical sensitization induced after the elicitation of CSD in the frontal cortex. TH (A) and STH $(\boldsymbol{B})$ responses in neurons that exhibited mechanical sensitization. Data depict the mean responses at baseline, before CSD, and during the time of peak response after CSD (range 30-135 min). C. Mean $\pm 95 \% \mathrm{Cl}$ of the latency to onset of persistent sensitization. $\boldsymbol{D}$, Duration of persistent sensitization. The means, indicated by circles ( $\pm 95 \% \mathrm{Cl})$, reflect data from afferents in which CSD-evoked changes in mechanical responsiveness were studied for up to $90 \min (n=13)$. The durations of sensitization of units in which post-CSD responses were recorded for up to $240 \mathrm{~min}(n=4)$ are indicated by asterisks. (E) Mean $\pm 95 \% \mathrm{Cl}$ of the magnitude increase in neuronal responses to TH and STH mechanical stimuli.

ularly contribute to the exacerbation of the headache in response to conditions that promote transient increases in intracranial pressure, such as straining (Greenfield et al., 1984) and coughing (Williams, 1976).

In response to CSD, some afferents were sensitized only at either the TH or STH level, suggesting that these two processes occur independently. The cellular mechanisms that underlie mechanical sensitization at the $\mathrm{TH}$ and STH levels in general are not well understood but likely involve modulation of different ionic currents that control mechanotransduction and repetitive firing. Of note, it has been shown previously that activation of at least one biochemical cascade (the CAMP-PKA cascade) can result in differential effects on the TH and STH responses (Levy and Strassman, 2002). However, the finding that, after CSD, the majority of the sensitized afferents were affected at both the TH and STH levels suggests the involvement of multiple signaling cascades (Levy and Strassman, 2002).

In the present study, it was observed that numerous afferents developed mechanical sensitization in response to CSD together with an increase in their ongoing activity rate. The data analyses conducted suggest, however, that these phenomena are not related, pointing to the possibility of two distinct underlying mechanisms. It is also worth noting that the mechanical sensitization response after CSD lasted longer than the increase in ongoing activity, suggesting that CSD-evoked mechanical sensitization of meningeal afferents may play a more substantial role in the development of migraine headache. The cellular and molecular mechanisms that contribute specifically to the sensitization of meningeal afferents after CSD re- main to be elucidated. The cortical depolarization that occurs during CSD gives rise to local release of numerous mediators with pro-nociceptive action, such as potassium, ATP, and arachidonic acid metabolites, into the interstitial space (Lauritzen et al., 1990; Schock et al., 2007; Enger et al., 2015). These and other algesic mediators such as nitric oxide (NO) may enter into the cerebrospinal fluid that circulates in the subarachnoid space (Shibata et al., 1991, 1992; Read et al., 1997), and if they reach a sufficient level, they could interact with meningeal afferents with RFs localized to the leptomeninges (Fricke et al., 1997, 2001), some of which may have collaterals that also terminate in the dura mater (O'Connor and van der Kooy, 1986; Kosaras et al., 2009). Interstitial mediators cleared via arachnoid granulations of the dural sinuses (Johnston et al., 2004) could act on meningeal afferents with RFs that terminate at these dural vascular locations. CSD-related parenchymal mediators that are cleared by the paravenous glymphatic pathway (lliff et al., 2012) and subsequently through the dural lymphatic network (Aspelund et al., 2015; Louveau et al., 2015) could influence dural afferents with RFs that terminate at the wall of dural lymphatic vessels (Andres et al., 1987). Dural afferents may also become sensitized in response to a secondary event, such as dural neurogenic inflammation, as hypothesized earlier (Moskowitz, 1993). Among the CSD-related mediators, the highly diffusible NO is of particular interest given its ability to promote mechanical sensitization of meningeal afferents without an increase in their ongoing activity (Zhang et al., 2013). The release of cyclooxygenase metabolites, which mediate the persistent post-CSD cerebral oligemic responses (Shibata et al., 

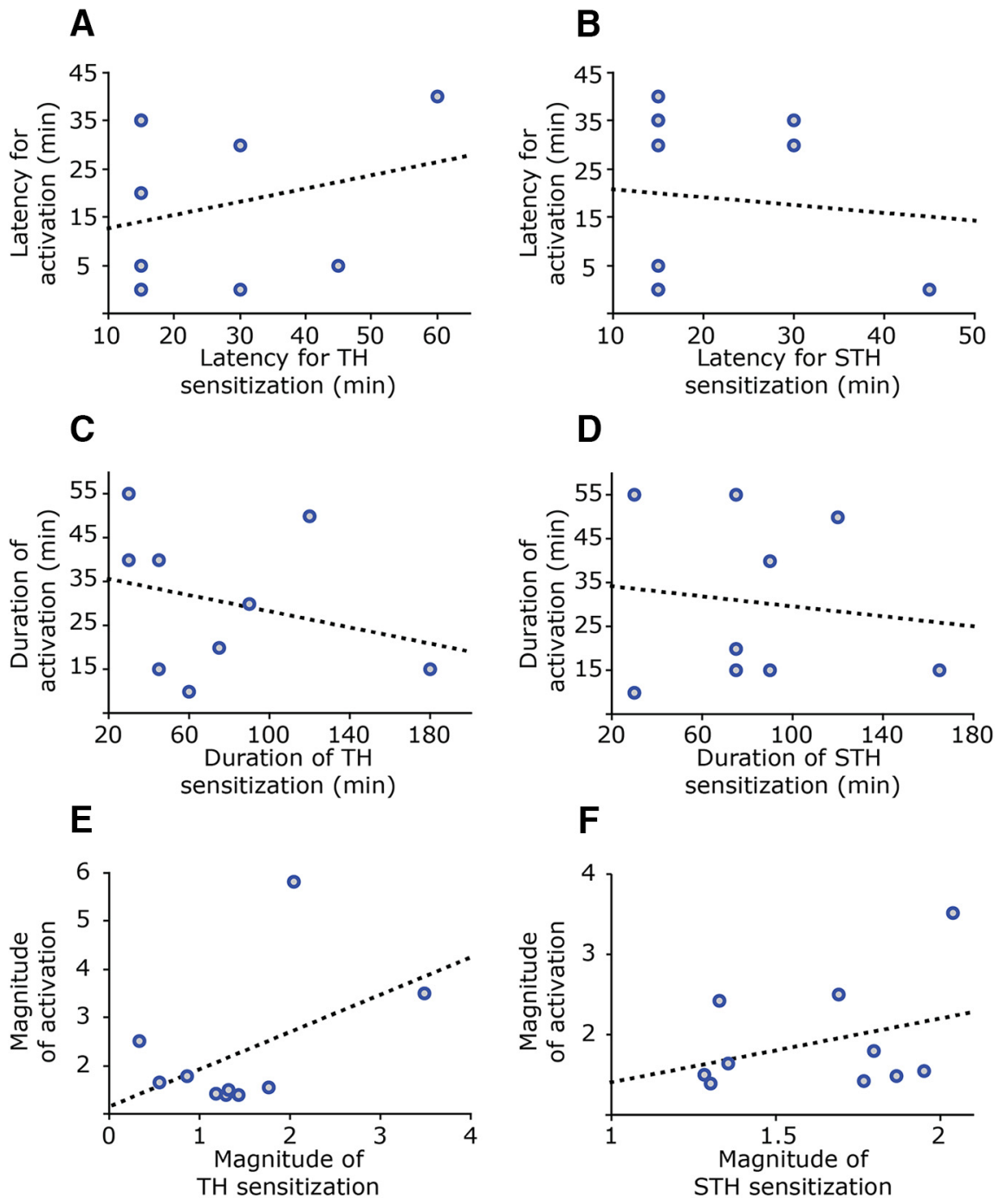

Figure 4. Mechanical sensitization of meningeal afferents induced after CSD is not correlated with the post-CSD increase in afferents' ongoing activity. Pearson's correlation indicated no linear relationship between the latency to onset of the sensitization and that of the increase in ongoing activity $(\boldsymbol{A}, \boldsymbol{B})$. There was no significant correlation between the duration of the sensitization response and the duration of the increase in ongoing activity $(\boldsymbol{C}, \boldsymbol{D})$. The magnitude of mechanical sensitization post-CSD was also not correlated with the magnitude of the increase in ongoing activity rate $(\boldsymbol{E}, \boldsymbol{F})$.

1992; Gariepy et al., 2016), may also contribute to the post-CSD afferent sensitization response (Levy et al., 2008). Importantly, however-because in some animals, mechanical sensitization was still present during the resolution of the oligemic response-it is unlikely that this cortical vascular response, in and of itself, is responsible for the persistence of the CSD-related mechanical sensitization.

In summary, the current study provides important in vivo data that further substantiate the role of trigeminal meningeal afferents in mediating migraine headache by showing that CSD, a putative migraine trigger, can lead to a pronounced and persistent sensitization of meningeal afferents. The development of mechanical sensitization of meningeal afferents, caused by CSD and perhaps other endogenous migraine triggering events, could serve as a key nociceptive process that mediates the exacerbation of the headache during conditions that momentarily increase intracranial pressure.

\section{References}

Amin FM, Asghar MS, Guo S, Hougaard A, Hansen AE, Schytz HW, van der Geest RJ, de Koning PJ, Larsson HB, Olesen J, Ashina M (2012) Headache and prolonged dilatation of the middle meningeal artery by PACAP38 in healthy volunteers. Cephalalgia 32:140149. CrossRef Medline

Amin FM, Hougaard A, Schytz HW, Asghar MS, Lundholm E, Parvaiz $\mathrm{Al}$, de Koning PJ, Andersen MR, Larsson HB, Fahrenkrug J, Olesen J, Ashina M (2014) Investigation of the pathophysiological mechanisms of migraine attacks induced by pituitary adenylate cyclase-activating polypeptide-38. Brain 137:779-794. CrossRef Medline

Andres KH, von Düring M, Muszynski K, Schmidt RF (1987) Nerve fibres and their terminals of the dura mater encephali of the rat. Anat Embryol (Berl) 175:289-301. Medline 
Aspelund A, Antila S, Proulx ST, Karlsen TV, Karaman S, Detmar M, Wiig H, Alitalo K (2015) A dural lymphatic vascular system that drains brain interstitial fluid and macromolecules. J Exp Med 212:991-999. CrossRef Medline

Ayata C, Jin H, Kudo C, Dalkara T, Moskowitz MA (2006) Suppression of cortical spreading depression in migraine prophylaxis. Ann Neurol 59:652-661. CrossRef Medline

Blau JN, Dexter SL (1981) The site of pain origin during migraine attacks. Cephalalgia 1:143-147. Medline

Bolay H, Reuter U, Dunn AK, Huang Z, Boas DA, Moskowitz MA (2002) Intrinsic brain activity triggers trigeminal meningeal afferents in a migraine model. Nat Med 8:136-142. CrossRef

Cao Y, Aurora SK, Nagesh V, Patel SC, Welch KM (2002) Functional MRI-BOLD of brainstem structures during visually triggered migraine. Neurology 59:72-78. Medline

Charles AC, Baca SM (2013) Cortical spreading depression and migraine. Nat Rev Neurol 9:637-644. CrossRef Medline

Enger R, Tang W, Vindedal GF, Jensen V, Johannes Helm P, Sprengel R, Looger LL, Nagelhus EA (2015) Dynamics of ionic shifts in cortical spreading depression. Cereb Cortex 25:4469-4476. CrossRef Medline

Fordsmann JC, Ko RW, Choi HB, Thomsen K, Witgen BM, Mathiesen C, Lonstrup M, Piilgaard H, MacVicar BA, Lauritzen M (2013) Increased 20-HETE synthesis explains reduced cerebral blood flow but not impaired neurovascular coupling after cortical spreading depression in rat cerebral cortex. J Neurosci 33:2562-2570. CrossRef

Fricke B, von Düring M, Andres KH (1997) Topography and immunocytochemical characterization of nerve fibers in the leptomeningeal compartments of the rat. A light- and electronmicroscopical study. Cell Tissue Res 287:11-22. CrossRef

Fricke B, Andres KH, Von Düring M (2001) Nerve fibers innervating the cranial and spinal meninges: morphology of nerve fiber terminals and their structural integration. Microsc Res Tech 53:96-105. CrossRef Medline

Gariepy H, Zhao J, Levy D (2016) Differential contribution of COX-1 and COX-2 derived prostanoids to cortical spreading depressionevoked cerebral oligemia. J Cereb Blood Flow Metab pii: 0271678X16650217. Medline

Greenfield JC, Jr., Rembert JC, Tindall GT (1984) Transient changes in cerebral vascular resistance during the Valsalva maneuver in man. Stroke 15:76-79. CrossRef

Hadjikhani N, Sanchez Del Rio M, Wu O, Schwartz D, Bakker D, Fischl B, Kwong KK, Cutrer FM, Rosen BR, Tootell RB, Sorensen AG, Moskowitz MA (2001) Mechanisms of migraine aura revealed by functional MRI in human visual cortex. Proc Natl Acad Sci U S A 98:4687-4692. CrossRef Medline

Hansen JM, Lipton RB, Dodick DW, Silberstein SD, Saper JR, Aurora SK, Goadsby PJ, Charles A (2012) Migraine headache is present in the aura phase: a prospective study. Neurology 79:2044-2049. CrossRef Medline

Iliff JJ, Wang M, Liao Y, Plogg BA, Peng W, Gundersen GA, Benveniste $H$, Vates GE, Deane R, Goldman SA, Nagelhus EA, Nedergaard M (2012) A paravascular pathway facilitates CSF flow through the brain parenchyma and the clearance of interstitial solutes, including amyloid beta. Sci Transl Med 4:147ra111. CrossRef Medline

Johnston M, Zakharov A, Papaiconomou C, Salmasi G, Armstrong D (2004) Evidence of connections between cerebrospinal fluid and nasal lymphatic vessels in humans, non-human primates and other mammalian species. Cerebrospinal Fluid Res 1:2. CrossRef

Karatas H, Erdener SE, Gursoy-Ozdemir Y, Lule S, Eren-Koçak E, Sen ZD, Dalkara T (2013) Spreading depression triggers headache by activating neuronal Panx1 channels. Science 339:1092-1095. CrossRef Medline

Kosaras B, Jakubowski M, Kainz V, Burstein R (2009) Sensory innervation of the calvarial bones of the mouse. $J$ Comp Neur 515:331-348. CrossRef Medline
Lauritzen M, Hansen AJ, Kronborg D, Wieloch T (1990) Cortical spreading depression is associated with arachidonic acid accumulation and preservation of energy charge. J Cereb Blood Flow Metab 10:115-122. CrossRef

Levy D, Strassman AM (2002) Distinct sensitizing effects of the CAMP-PKA second messenger cascade on rat dural mechanonociceptors. J Physiol (Lond) 538:483-493. CrossRef

Levy D, Strassman AM (2004) Modulation of dural nociceptor mechanosensitivity by the nitric oxide-cyclic GMP signaling cascade. J Neurophysiol 92:766-772. Medline

Levy D, Zhang XC, Jakubowski M, Burstein R (2008) Sensitization of meningeal nociceptors: inhibition by naproxen. Eur J Neurosci 27:917-922. CrossRef Medline

Louveau A, Smirnov I, Keyes TJ, Eccles JD, Rouhani SJ, Peske JD, Derecki NC, Castle D, Mandell JW, Lee KS, Harris TH, Kipnis J (2015) Structural and functional features of central nervous system lymphatic vessels. Nature 523:337-341. CrossRef Medline

Messlinger K (2009) Migraine: where and how does the pain originate? Exp Brain Res 196:179-193. CrossRef Medline

Moskowitz MA (1984) The neurobiology of vascular head pain. Ann Neurol 16:157-168. CrossRef Medline

Moskowitz MA (1993) Neurogenic inflammation in the pathophysiology and treatment of migraine. Neurology 43:S16-S20. Medline

Moskowitz MA, Nozaki K, Kraig RP (1993) Neocortical spreading depression provokes the expression of $\mathrm{C}$-fos protein-like immunoreactivity within trigeminal nucleus caudalis via trigeminovascular mechanisms. J Neurosci 13:1167-1177. Medline

Noseda R, Burstein R (2013) Migraine pathophysiology: anatomy of the trigeminovascular pathway and associated neurological symptoms, cortical spreading depression, sensitization, and modulation of pain. Pain 154:S44-S53. CrossRef

O'Connor TP, van der Kooy D (1986) Pattern of intracranial and extracranial projections of trigeminal ganglion cells. J Neurosci 6:2200-2207. Medline

Olesen J, Burstein R, Ashina M, Tfelt-Hansen P (2009) Origin of pain in migraine: evidence for peripheral sensitisation. Lancet Neurol 8:679-690. CrossRef Medline

Pietrobon D, Moskowitz MA (2012) Pathophysiology of migraine. Ann Rev Physiol 15:S15-S22. Medline

Read SJ, Smith MI, Hunter AJ, Parsons AA (1997) The dynamics of nitric oxide release measured directly and in real time following repeated waves of cortical spreading depression in the anaesthetised cat. Neurosci Lett 232:127-130. Medline

Russo AF (2015) Calcitonin gene-related peptide (CGRP): a new target for migraine. Annu Rev Pharmacol Toxicol 55:533-552. CrossRef Medline

Schock SC, Munyao N, Yakubchyk Y, Sabourin LA, Hakim AM, Ventureyra EC, Thompson CS (2007) Cortical spreading depression releases ATP into the extracellular space and purinergic receptor activation contributes to the induction of ischemic tolerance. Brain Res 1168:129-138. CrossRef Medline

Shibata M, Leffler CW, Busija DW (1991) Evidence against parenchymal metabolites directly promoting pial arteriolar dilation during cortical spreading depression in rabbits. Brain Res Bull 26: 753-758. Medline

Shibata M, Leffler CW, Busija DW (1992) Pial arteriolar constriction following cortical spreading depression is mediated by prostanoids. Brain Res 572:190-197. Medline

Steiner TJ, Stovner LJ, Birbeck GL (2013) Migraine: the seventh disabler. J Headache Pain 14:1. CrossRef Medline

Stovner L, Hagen K, Jensen R, Katsarava Z, Lipton R, Scher A, Steiner T, Zwart JA (2007) The global burden of headache: a documentation of headache prevalence and disability worldwide. Cephalalgia 27:193-210. CrossRef Medline

Strassman AM, Levy D (2006) Response properties of dural nociceptors in relation to headache. J Neurophysiol 95:1298-1306. CrossRef Medline

Strassman AM, Raymond SA, Burstein R (1996) Sensitization of meningeal sensory neurons and the origin of headaches. Nature 384:560-564. CrossRef Medline 
Williams B (1976) Cerebrospinal fluid pressure changes in response to coughing. Brain 99:331-346. Medline

Zhang X, Kainz V, Zhao J, Strassman AM, Levy D (2013) Vascular extracellular signal-regulated kinase mediates migraine-related sensitization of meningeal nociceptors. Ann Neurol 73:741-750. CrossRef Medline

Zhang X, Levy D, Noseda R, Kainz V, Jakubowski M, Burstein R (2010) Activation of meningeal nociceptors by cortical spreading depression: implications for migraine with aura. J Neurosci 30: 8807-8814. CrossRef Medline

Zhang X, Levy D, Kainz V, Noseda R, Jakubowski M, Burstein R (2011) Activation of central trigeminovascular neurons by cortical spreading depression. Ann Neurol 69:855-865. CrossRef Medline

Zhao J, Levy D (2015) Modulation of intracranial meningeal nociceptor activity by cortical spreading depression: a reassessment. $J$ Neurophysiol 113:2778-2785. CrossRef Medline 